\title{
FOOD HABITS OF COYOTES, GRAY FOXES, AND BOBCATS IN A COASTAL SOUTHERN CALIFORNIA URBAN LANDSCAPE
}

\author{
Rachel N. Larson ${ }^{1,3}$, Dana J. Morin ${ }^{1}$, Izabela A. Wierzbowska ${ }^{2}$, and Kevin R. Crooks ${ }^{1}$
}

\begin{abstract}
Many carnivores are sensitive to habitat fragmentation, and the capacity to shift diets may improve their ability to persist in urban areas. We collected and identified contents of a total of 119 scats from coyotes (Canis latrans), 58 scats from gray foxes (Urocyon cinereoargenteus), and 31 scats from bobcats (Lynx rufus) within habitat fragments of varying size in the San Diego area in coastal southern California. Coyote diet was generalist, composed of mostly mammals but also anthropogenic items, fruit and seeds, birds, and invertebrates. Dietary breadth of coyotes was similar in small urban habitat fragments and larger sites, but composition differed, suggestive of the opportunistic habits of coyotes. Notably, domestic cats occurred in $29 \%$ of coyote scats in small urban fragments, implicating coyotes as a threat to cats. Like coyotes, gray foxes had an omnivorous diet consisting of mammals, fruit and seeds, invertebrates, and birds. As with coyotes, dietary breadth of gray foxes was similar in urban habitat remnants and larger control sites. Bobcats, not detected in small urban fragments, had a more specialized diet focused primarily on mammalian prey. Such resource specialization might limit bobcats' ability to exploit anthropogenic subsidies and hence persist in small urban patches, compared to more opportunistic carnivores such as coyotes and gray foxes.
\end{abstract}

Resumen.-Muchos carnívoros son susceptibles a la fragmentación del hábitat y la capacidad de cambiarse la dieta puede que mejore la capacidad de algunos especies a persistir en los areas urbanos. Recogimos y identificamos los contenidos de un total de 119 excrementos de los coyotes (Canis latrans), 58 excrementos de los zorros grises (Urocyon cineroargenteus), y 31 excrementos de los linces rojos (Lynx rufus) en los terrenos del hábitat de tamaños varios en el area de San Diego en la costa del sur de California. La dieta de los coyotes fue generalista, compuesto sobre todo de los mamiferos, sino también los artículos antropogénicos, las frutas y semillas, los pájaros, y los invertebrados. La anchura dietética de los coyotes fue similar en los terrenos pequeños urbanos y los sitios más grandes, pero la composición difirió, sugestivo de los hábitos oportunistas de los coyotes. Particularmente, los gatos domesticados ocurrieron en 29\% de los excrementos de los coyotes en terrenos pequeños urbanos, implicando a los coyotes como una amenza a los gatos. Como los coyotes, los zorros grises tuvieron una dieta omnívora consistiendo en los mamíferos, las frutas y semillas, los invertebrados, y los pájaros. Como sucede con los coyotes, la anchura dietética de los zorros grises fue similar en remanentes pequeños de la hábitat y sitios de control más grandes. Los linces rojos, que no fueron detectados en los terrenos pequeños, tuvieron una dieta más especializada que puso el acento principalmente en la presa del mamífero. Eses tipos de especializaciónes de los recursos puede que limite su hábilidad a explotar los subsidios anthropogénicos y así que persistir en terrenos pequeños urbanos comparado con los carnívoros más oportunistas como los coyotes y zorros grises.

Habitat loss and fragmentation is a primary threat to biological diversity (Wilcove et al. 1998, Fahrig 2003, Schipper et al. 2008) and urbanization is a leading agent of fragmentation (Czech et al. 2000, McDonald et al. 2008). Mammalian carnivores, due to their large home ranges and low densities, are particularly sensitive to urban fragmentation effects (Crooks 2002, Ordeñana et al. 2010, Gehrt et al. 2010). However, their responses vary, with some species increasing and some decreasing activity in urban areas (Crooks 2002, Tigas et al. 2002, Bateman and Fleming 2012). Urban environments not only alter the distribution and density of carnivore populations, but can also influence available forage and hence diets of urban carnivores (McClure et al. 1995, Gehrt et al. 2010). For example, predators may shift their diet in urban areas to consume more anthropogenic food items, including trash, cultivated fruits, and domestic pets (Fedriani et al. 2001, Silverstein 2004).

The South Coast Ecoregion of southern California is the largest metropolitan area in the USA (Beier et al. 2006), yet populations of mammalian carnivores, such as bobcats (Lynx rufus), coyotes (Canis latrans), and gray foxes (Urocyon cinereoargenteus), can still persist there (Crooks 2002, Riley et al. 2003, Ordeñana et al. 2010). In general, bobcats are

\footnotetext{
${ }^{1}$ Department of Fish, Wildlife, and Conservation Biology, Warner College of Natural Resources, Colorado State University, Fort Collins, CO 80523. ${ }^{2}$ Institute of Environmental Sciences, Jagiellonian University, 7 Gronostajowa, 30-387 Krakow, Poland.

${ }^{3}$ E-mail: rlarson92@gmail.com
} 
typically identified as strict carnivores (Larivière and Walton 1997, Riley et al. 2010). In contrast, coyotes have a more variable, omnivorous diet that can be relatively plastic (Bekoff 1977, Gehrt and Riley 2010). For example, in the Santa Monica Mountains north of Los Angeles, Fedriani et al. (2001) found that increasing urbanization correlated with elevated population densities of coyotes and their consumption of human-related food items. Coyotes also subsidize their diet with domestic cats in urban systems (Crooks and Soulé 1999, Gehrt et al. 2013). Like coyotes, gray foxes have a varied and omnivorous diet (Fritzell and Haroldson 1982), although food habits of gray foxes in urban areas have received little attention (but see Riley 2001, Riley and White 2010).

Although prior research has documented food habits of bobcats, coyotes, and gray foxes, few studies have directly compared their diets or evaluated how they vary across landscapes that differ in degree of urbanization. Our goal was to describe and compare the diets of bobcats, coyotes, and gray foxes in habitat fragments of varying size, including small and isolated urban habitat remnants and larger contiguous habitat blocks in coastal southern California. We expected that the composition and breadth of carnivore diets would differ among species and between small and large fragments in urban environments.

\section{METHODS}

Coyote, bobcat, and gray fox scats were collected from September 1995 through August 1997 from undeveloped habitat fragments within the urban landscape of San Diego and Orange Counties, California. Designated transects were established along prominent dirt roads or trails (human and/or wildlife) along the main axis of each study area. All existing scats were initially cleared from transects within each site, and then all newly deposited scats were collected twice (after 2 weeks and 1 month) following clearing. Scat surveys were conducted quarterly in each site; limited sample size, however, precluded seasonal analyses of diet. Each site was sampled for 1-2 years and therefore 4-8 times total.

Scats were identified in the field based on morphology (length, width, and shape), odor, color, location, and nearby sign, including tracks and scrapes; distinguishing characteristics were developed from scats of known origin, as well as scientific publications and field guides with scat descriptions (Murie 1954, Danner and Dodd 1982, Halfpenny 1986, Rezendes 1992). Ongoing research in the study area included concurrent track station and remote camera surveys, as well as questionnaire surveys to adjacent residents, which provided additional information as to the occurrence of carnivore species in each site. For example, scats deposited directly on track stations, and thus associated with diagnostic tracks, provided high confidence of species identification. Carnivore distribution also differed among fragments of varying size, age, and isolation (Crooks and Soulé 1999, Crooks 2002), further facilitating scat identification given that species were not present at all sites or varied in their temporal visitation to a fragment. For example, coyotes were not detected in some of the smaller urban fragments, and they visited other urban fragments only temporarily (Crooks and Soulé 1999, Crooks 2002); absence of coyotes increased confidence of identification of gray fox scat collected during those periods. Using the field identification criteria, as well as information on species occurrence as determined by the concurrent track, camera, and questionnaire surveys, each collected scat was assigned a reliability score of correct species identification, ranging from 3 (highly reliable) to 0 (no species identification possible). To ensure consistency in identification, only one researcher (KRC) assigned reliability scores and determined species of origin, and only scats assigned a reliability score of 3 were included in the diet analyses.

Following Crooks (2002), scats were assigned to "small" and "large" fragments based on their size, isolation, and landscape context (for maps of the study area and location of the fragments, see Soulé et al. 1988, Bolger et al. 1997, Suarez et al. 1998). The small fragments $(n=19)$ were typically canyons dissecting costal mesas and were entirely surrounded by urban development of San Diego and neighboring cities; as such, these canyons essentially persist as habitat "islands" immersed within an urban matrix (Soulé et al. 1988, Crooks and Soulé 1999, Crooks 2002). These urban canyons supported a mosaic of chaparral, succulents, and sage scrub vegetation and 
ranged in size from 2 to 102 ha $(\bar{x}=21.5, \mathrm{SD}$ 26.6). The large habitat patches $(n=4)$ ranged in size from 264 to 5806 ha $(\bar{x}=2011.5$, SD 2245.8) and were selected to act as controls to the small, urban habitat remnants. They were less disturbed than the small fragments and included ecological reserves in urban areas (Point Loma Ecological Reserve and Torrey Pines State Reserve in San Diego), as well as blocks of natural habitat adjacent to larger natural areas (Miramar Marine Corps Air Station in San Diego County and Starr Ranch Audubon Sanctuary in Orange County; see Table 1 in Crooks 2002 for descriptions of these study sites).

Collected scats were initially frozen, then washed and dried inside nylon hose to collect ingested material, including hair, bone, fruit, and seeds. All ingested items were dried and transferred to envelopes for storage. Food items were classified as mammals (to taxonomic family where possible), birds, invertebrates, fruit and seeds, and anthropogenic items, including trash and 2 human commensal species, domestic cat Felis catus (following Gehrt and Riley 2010) and house mouse Mus musculus.

To identify mammals, samples of hair from each scat were made into 3 different types of slides: medulla, scale, and cross-section. Medulla slides visualized the outside structures of the hair, scale slides examined the scales on individual hairs, and cross-section slides allowed observation of internal hair structures. Slides were viewed under microscopes (Nikon Eclipse 80i, Carl Zeiss Standard 18) and photographed with accompanying digital cameras to enable comparison of samples to identification keys (e.g., Mayer 1952, Moore et al. 1974, Tumlison 1983, Teerink 1991). Samples were also identified by patterns on the occlusal surfaces of molars, if present, in the scat (Chomko 1980).

For each target species (coyote, gray fox, and bobcat), we determined both the frequency of occurrence (FO) and percentage of occurrence $(\mathrm{PO})$ of prey items in scats (Zabala and Zuberogoitia 2003, van Dijk et al. 2007, Klare et al. 2011). FO was calculated as

$$
\mathrm{FO}_{i}(\%)=\left(n_{i} / N\right) * 100,
$$

where $n_{i}$ is the number of scats containing a prey item $i$ and $N$ is the total number of scats.
Thus, FO measures the percentage of scats that contain a given prey item. PO was calculated as

$$
\mathrm{PO}_{i}(\%)=\left(n_{i} / \sum n_{i}\right) * 100 .
$$

Thus, PO measures the contribution of each prey item $i$ expressed as a percentage of the total number of occurrences of all food items. Although FO and PO do not necessarily approximate the volumetric importance of items in the diet, they can provide valuable insight into carnivore ecology (Klare et al. 2011). Both FO and PO are highly concordant in their rankings of food items in carnivore diets (Zabala and Zuberogoitia 2003, van Dijk et al. 2007, Klare et al. 2011). We focus our result summary on FO because it is the most frequently used method in diet studies and is readily interpretable (Zabala and Zuberogoitia 2003, Klare et al. 2011), but we also present PO to enable comparison with other diet studies that have used this metric.

Additionally, a niche breadth statistic $(B)$ was calculated for each predator for each fragment size category (Pianka 1973, Neale and Sacks 2001):

$$
B=1 / \sum p_{i}{ }^{2},
$$

where $p_{i}$ is the proportion of prey item $i$ in the diet, calculated by dividing the number of scats containing prey item $i\left(n_{i}\right)$ by the sum of all scats containing each prey item $\left(\sum n_{i}\right)$ :

$$
p_{i}=\left(n_{i} / \sum n_{i}\right) .
$$

To calculate the niche breadth statistic, we evaluated 10 prey item categories, including fruit and seeds, birds, invertebrates, anthropogenic items, and 6 mammalian taxonomic orders: Rodentia (rodents), Lagomorpha (rabbits and hares), Carnivora (carnivores), Artiodactyla (black-tailed deer Odocoileus hemionus), Soricomorpha (shrews and moles), and Didelphimorpha (Virginia opossum Didelphis virginiana). Because we evaluated 10 prey item categories, $B$ can range from 1 (the predator only consumes one type of prey item) to 10 (the predator consumes all 10 types of prey item in equal frequencies). Numerous scats $(n$ $=134,64.4 \%$ ) contained more than one prey item, so $\sum n_{i}>N$. Finally, we used chi-square goodness-of-fit analyses to test whether the 
TABLE 1. The occurrences of prey items in 119 coyote scats, categorized by habitat fragment size (small fragment: 2-102 ha; large fragment: 264-5806 ha) and identified to taxonomic family where possible. Within each category, $N=$ total number of scats, $n_{i}=$ number of scats containing a prey item, FO is frequency of occurrence, and PO is percent occurrence. A niche breadth statistic $(B)$ is also presented for each fragment category (see text). Within each prey item category, identified items are listed in descending order of FO across all sites.

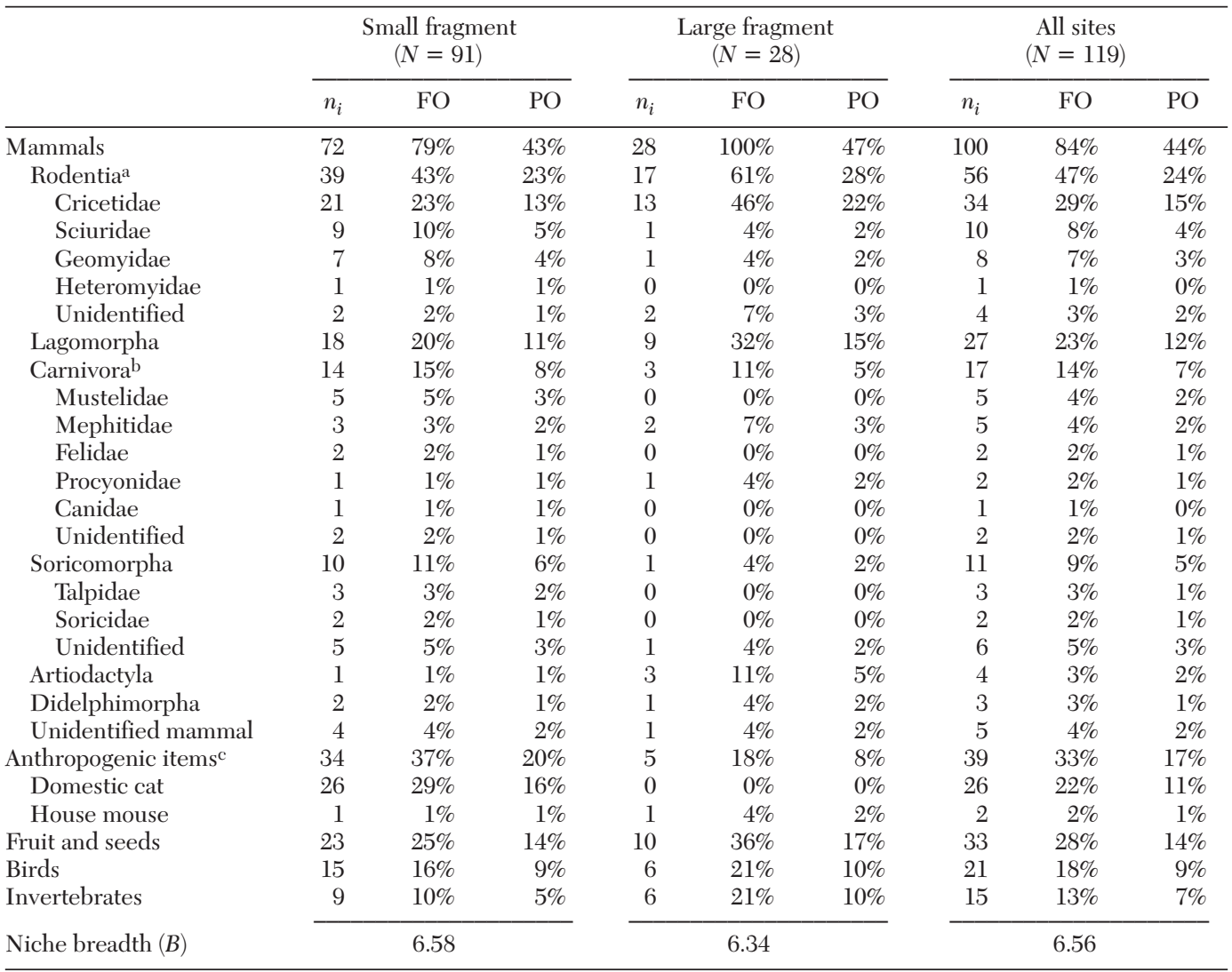

axcludes house mouse Mus musculus.

bexcludes domestic cat Felis cattus.

cIncludes anthropogenic items such as trash (tinfoil, thread, plastic, paper, and bandages) and 2 commensal species (house mouse and domestic cat).

distribution of prey items among the 10 categories varied between small and large fragment types and between species; bobcats were detected only in large fragments, so chi-square tests focused on comparisons with coyotes and gray foxes in large fragments specifically.

\section{RESULTS}

A total of 208 scats from 3 species of carnivore were analyzed. 136 scats were collected in small fragments (range $2-12$ per fragment; $\bar{x}$ $=7.1, \mathrm{SD} 3.0$ ) and 72 were collected in large fragments (range 4-37 per fragment; $\bar{x}=18$, SD 12.1). Of these scats, 119 were identified as coyote, 58 as gray fox, and 31 as bobcat.

\section{Coyotes}

Of the 119 coyote scats, 91 were from small fragments and 28 were from large fragments (Table 1). The dietary niche breadth of coyotes was similar (3.8\% difference) between small fragments $(B=6.58)$ and large fragments $(B=6.34)$. Likewise, prey item distribution across the 10 primary prey item categories did not significantly differ between coyote scats in large and small fragments $\left(\chi^{2}=\right.$ 13.6 , $\mathrm{df}=9, P=0.136)$. Overall dietary niche breadth for coyotes $(B=6.56)$ was $117.1 \%$ that of gray foxes $(B=5.60$; Table 2$)$ and $281.5 \%$ that of bobcats $(B=2.33$; Table 3$)$. Prey item distribution across the 10 categories differed significantly between coyote and gray fox scats pooled across fragment types 
TABLE 2. The occurrences of prey items in 58 gray fox scats, categorized by habitat fragment size (small fragment: 2-102 ha; large fragment: 264-5806 ha) and identified to taxonomic family where possible. Within each size category, $N=$ total number of scats, $n_{i}=$ number of scats containing a prey item, FO is frequency of occurrence, and PO is percent occurrence. A niche breadth statistic $(B)$ is also presented for each fragment size category (see text). Within each prey item category, identified items are listed in descending order of FO across all sites.

\begin{tabular}{|c|c|c|c|c|c|c|c|c|c|}
\hline & & $\begin{array}{l}\text { all fras } \\
(N=\end{array}$ & & & $\begin{array}{l}\text { ge fragr } \\
(N=13\end{array}$ & & & $\begin{array}{l}\text { All site } \\
N=58\end{array}$ & \\
\hline & $n_{i}$ & FO & $\mathrm{PO}$ & $n_{i}$ & $\mathrm{FO}$ & $\mathrm{PO}$ & $n_{i}$ & $\mathrm{FO}$ & $\mathrm{PO}$ \\
\hline Mammals & 38 & $84 \%$ & $48 \%$ & 13 & $100 \%$ & $68 \%$ & 51 & $88 \%$ & $50 \%$ \\
\hline Rodentiab & 22 & $49 \%$ & $28 \%$ & 8 & $62 \%$ & $42 \%$ & 30 & $52 \%$ & $29 \%$ \\
\hline Cricetidae & 12 & $27 \%$ & $15 \%$ & 7 & $54 \%$ & $37 \%$ & 19 & $33 \%$ & $19 \%$ \\
\hline Sciuridae & 5 & $11 \%$ & $6 \%$ & 0 & $0 \%$ & $0 \%$ & 5 & $9 \%$ & $5 \%$ \\
\hline Geomyidae & 1 & $2 \%$ & $1 \%$ & 1 & $8 \%$ & $5 \%$ & 2 & $3 \%$ & $2 \%$ \\
\hline Unidentified & 4 & $9 \%$ & $5 \%$ & 0 & $0 \%$ & $0 \%$ & 4 & $7 \%$ & $4 \%$ \\
\hline Soricomorpha & 5 & $11 \%$ & $6 \%$ & 4 & $31 \%$ & $21 \%$ & 9 & $16 \%$ & $9 \%$ \\
\hline Soricidae & 4 & $9 \%$ & $5 \%$ & 2 & $15 \%$ & $11 \%$ & 6 & $10 \%$ & $6 \%$ \\
\hline Unidentified & 1 & $2 \%$ & $1 \%$ & 2 & $15 \%$ & $11 \%$ & 3 & $5 \%$ & $3 \%$ \\
\hline Carnivora $^{\mathrm{c}}$ & 7 & $16 \%$ & $9 \%$ & 1 & $8 \%$ & $5 \%$ & 8 & $14 \%$ & $8 \%$ \\
\hline Mephitidae & 3 & $7 \%$ & $4 \%$ & 0 & $0 \%$ & $0 \%$ & 3 & $5 \%$ & $3 \%$ \\
\hline Mustelidae & 2 & $4 \%$ & $3 \%$ & 0 & $0 \%$ & $0 \%$ & 2 & $3 \%$ & $2 \%$ \\
\hline Procyonidae & 0 & $0 \%$ & $0 \%$ & 1 & $8 \%$ & $5 \%$ & 1 & $2 \%$ & $1 \%$ \\
\hline Unidentified & 2 & $4 \%$ & $3 \%$ & 0 & $0 \%$ & $0 \%$ & 2 & $3 \%$ & $2 \%$ \\
\hline Lagomorpha & 3 & $7 \%$ & $4 \%$ & 1 & $8 \%$ & $5 \%$ & 4 & $7 \%$ & $4 \%$ \\
\hline Didelphimorpha & 1 & $2 \%$ & $1 \%$ & 0 & $0 \%$ & $0 \%$ & 1 & $2 \%$ & $1 \%$ \\
\hline Artiodactyla & 0 & $0 \%$ & $0 \%$ & 1 & $8 \%$ & $5 \%$ & 1 & $2 \%$ & $1 \%$ \\
\hline Unidentified mammal & 3 & $7 \%$ & $4 \%$ & 2 & $15 \%$ & $11 \%$ & 5 & $9 \%$ & $5 \%$ \\
\hline Fruit and seeds & 22 & $49 \%$ & $28 \%$ & 3 & $23 \%$ & $16 \%$ & 25 & $43 \%$ & $25 \%$ \\
\hline Invertebrates & 10 & $22 \%$ & $13 \%$ & 2 & $15 \%$ & $11 \%$ & 12 & $21 \%$ & $12 \%$ \\
\hline Anthropogenic items ${ }^{\mathrm{d}}$ & 6 & $13 \%$ & $8 \%$ & 1 & $8 \%$ & $5 \%$ & 7 & $12 \%$ & $7 \%$ \\
\hline Domestic cat & 2 & $4 \%$ & $3 \%$ & 0 & $0 \%$ & $0 \%$ & 2 & $3 \%$ & $2 \%$ \\
\hline House mouse & 1 & $2 \%$ & $1 \%$ & 0 & $0 \%$ & $0 \%$ & 1 & $2 \%$ & $1 \%$ \\
\hline Birds & 7 & $16 \%$ & $9 \%$ & 0 & $0 \%$ & $0 \%$ & 7 & $12 \%$ & $7 \%$ \\
\hline Niche breadth $(B)$ & & 5.57 & & & 4.55 & & & 5.60 & \\
\hline
\end{tabular}

aLow sample size limits inferential strength, but data are provided for comparative purposes.

${ }^{\mathrm{b}}$ Excludes house mouse Mus musculus.

cExcludes domestic cat Felis cattus.

${ }^{\mathrm{d}}$ Includes anthropogenic items such as trash (tinfoil and peanut shells) and 2 commensal species (house mouse and domestic cat.)

$\left(\chi^{2}=19.4, \mathrm{df}=9, P=0.022\right)$ and between coyote and bobcat scats within large fragments specifically $\left(\chi^{2}=22.5\right.$, df $\left.=9, P=0.007\right)$.

Pooled across fragment types, mammals were the predominant food item in coyote scats, followed by anthropogenic items, fruit and seeds, birds, and invertebrates. Of mammals, rodents were the most frequently detected prey item in both small and large fragments, followed by lagomorphs. Within the rodents, Cricetidae were most prevalent, including woodrats (Neotoma spp.), deer mice (Peromyscus spp.), California vole (Microtus californicus), and western harvest mouse (Reithrodontomys megalotis). Sciurid rodents (tree squirrels Sciurus spp.; California ground squirrel Otospermophilus beecheyi) and geomyid rodents (valley pocket gopher Thomomys bottae) were less frequently detected, and a heteromyid rodent (kangaroo rat Dipodomys spp.) was found in one small-fragment scat. Carnivore remains were occasionally detected in coyote scats from both small and large fragments; Carnivora (excluding domestic cats) included Mustelidae (long-tailed weasel Mustela frenata), Mephitidae (striped skunk Mephitis mephitis; spotted skunk Spilogale gracilis), Felidae (bobcat Lynx rufus), Procyonidae (raccoon Procyon lotor), and Canidae (gray fox). Soricomorpha (Soricidae: shrews; Talpidae: broad-footed mole Scapanus latimanus), Didelphimorpha (Virginia opossum), and Artiodactyla (black-tailed deer) were infrequently detected in both fragment types.

Anthropogenic items, including domestic cat, house mouse, and trash (e.g., tinfoil, thread, plastic, paper, and bandanges), were found in $37 \%$ of small-fragment scats and $18 \%$ of largefragment scats. Specifically, domestic cats were found in $29 \%$ of coyote scats from small 
TABLE 3. The occurrences of prey items in 31 bobcat scats; bobcats were detected only in large fragments (range 264-5806 ha), and prey items were identified to taxonomic family where possible. $N=$ total number of scats, $n_{i}=$ number of scats containing a prey item, $\mathrm{FO}$ is frequency of occurrence, and PO is percent occurrence. A niche breadth statistic $(B)$ is also presented (see text). Within each prey item category, identified items are listed in descending order of $\mathrm{FO}$ across all sites.

\begin{tabular}{lrrr}
\hline & \multicolumn{3}{c}{$\begin{array}{c}\text { Large fragmenta } \\
\end{array}$} \\
\cline { 2 - 4 } & $n_{i}$ & FO & PO \\
\hline Mammals & 31 & $100 \%$ & $65 \%$ \\
$\quad$ Rodentia & 30 & $97 \%$ & $63 \%$ \\
$\quad$ Cricetidae & 24 & $77 \%$ & $50 \%$ \\
$\quad$ Sciuridae & 5 & $16 \%$ & $10 \%$ \\
$\quad$ Geomyidae & 1 & $3 \%$ & $2 \%$ \\
$\quad$ Unidentified rodent & 3 & $10 \%$ & $6 \%$ \\
Lagomorpha & 6 & $19 \%$ & $13 \%$ \\
Didelphimorpha & 1 & $3 \%$ & $2 \%$ \\
Invertebrates & 5 & $16 \%$ & $10 \%$ \\
Birds & 5 & $16 \%$ & $10 \%$ \\
Fruit and seeds & 1 & $3 \%$ & $2 \%$ \\
Niche breadth $(B)$ & \multicolumn{3}{c}{2.33} \\
\hline
\end{tabular}

a Large fragments are $>102$ ha.

fragments, but not in scats from large fragments. Fruit and seeds, birds, and invertebrates were also detected in scats from both fragment types.

\section{Gray Foxes}

Of the 58 gray fox scats, 45 were from small fragments and 13 were from large fragments (Table 2). The dietary niche breadth of gray foxes was similar (22.4\% difference) between small fragments $(B=5.57)$ and large fragments $(B=4.55)$. Likewise, prey item distribution across the 10 categories did not significantly differ between gray fox scats from large and small fragments $\left(\chi^{2}=11.7, \mathrm{df}=9\right.$, $P=0.232$ ), although sample size was low in large fragments, limiting inference. Pooled across fragments, overall dietary niche breadth for gray foxes $(B=5.60)$ was $240.3 \%$ that of bobcats $(B=2.33$; Table 3$)$. For large fragments specifically, prey item distribution across the 10 primary categories significantly differed between gray fox scats and bobcat scats $\left(\chi^{2}=24.8, \mathrm{df}=9, P=0.003\right)$.

Pooled across fragment types, mammals were the predominant prey items in gray fox scats, followed by fruit and seeds, invertebrates, anthropogenic items, and birds. Of mammals, rodents were the most frequently detected prey item in both large and small fragments, primarily Cricetidae, followed by Sciuridae and Geomyidae. Soricomorpha (Soricidae: shrews) were also detected in scats from both large and small fragments. Carnivore remains were occasionally detected in gray fox scats; Carnivora (excluding domestic cats) included Mephitidae (striped skunk, spotted skunk), Mustelidae (long-tailed weasel), and Procyonidae (raccoon). Lagomorpha were infrequently detected in scats from both fragment types. Didelphimorpha (Virginia opossum) occurred in only one small-fragment scat and Artiodactyla (black-tailed deer) occurred in only one large-fragment scat.

Fruit and seeds were present in $49 \%$ of small-fragment scats but only in $23 \%$ of scats from large fragments. Invertebrates occurred in scats from both large and small fragments, and birds were recorded in only small-fragment scats. Anthropogenic items were found in 6 small-fragment scats and one large-fragment scat. Specifically, domestic cats were found in 2 small-fragment scats and no large-fragment scats.

\section{Bobcats}

All 31 bobcat scats were from large fragments; no bobcats were detected in small fragments (Table 3; see also Crooks 2002 for data on distribution of bobcats in this study system). The dietary niche breadth of bobcat was $B=2.33,36.8 \%$ that of coyotes $(B=6.34)$ and $51.2 \%$ that of gray foxes $(B=4.55)$ in large fragments specifically.

Mammals were the predominant prey item in bobcat scats, followed by invertebrates and birds. Seeds were detected in one bobcat scat. Of mammals, rodents were most prevalent, primarily Cricetidae, followed by Sciuridae and Geomyidae. Lagomorphs were the next most frequently detected mammal in bobcat scats. There was a single occurrence of an opossum. No domestic cats or items of anthropogenic origin were detected in bobcat scats.

\section{Discussion}

As expected, carnivore diet, as evident by prey items in scats, differed among species and among fragment types. Coyote diet was varied, composed of mostly mammals but also anthropogenic items, fruit and seeds, birds, and invertebrates. Dietary breadth of coyotes was similar in small urban habitat fragments 
and larger control sites, but composition differed, suggestive of the opportunistic habits of coyotes. Indeed, coyotes are generalist foragers that frequent urban areas in this system (Crooks 2002) and elsewhere, consuming human garbage, cultivated fruits and vegetables, and pets (e.g., Quinn 1997, Baker and Timm 1998, Fedriani et al. 2001, Gehrt and Riley 2010, Gehrt et al. 2013). Most notably, in our study, $29 \%$ of coyote scats in the small urban fragments contained domestic cats, but cat remains were absent in scats from large fragments. Interestingly, the frequency of cats we recorded in coyote scats in the San Diego canyons is considerably greater than that typically recorded for urban coyotes (Gehrt and Riley 2010). Free-ranging cats in this system originate from residences bordering the canyons, and concurrent track stations frequently detected both cats and coyotes along the developed edges of the small fragments but did not detect cats within the interior of the larger control sites (Crooks 2002). We suspect the small size of these urban habitat "islands," which were completely encircled by development, elevated the number of outdoor cats available to coyotes along patch edges. Indeed, questionnaire surveys distributed to adjacent residences suggested a high density of free-ranging cats bordering these urban canyons. Nearly one-third of residents owned cats, and on average each owner owned 1.7 cats. Over three-fourths of owners let their cats outdoors, resulting in dozens of outdoor cats surrounding a moderately sized fragment (ca. $20 \mathrm{ha}$ ) bordered by 100 residences (Crooks and Soulé 1999). Our results thus confirm that coyotes are subsidizing their diets with domestic cats in this urban system and represent a distinct threat to free-ranging cats. Such interactions can lead to increased conflict with humans in urban areas (e.g., Lukasik and Alexander 2011, Poessel et al. 2013). However, domestic cats also represent a threat to wildlife, especially avifauna (Crooks and Soulé 1999, Bonnington et al. 2013). Coyote predation on domestic cats may therefore help protect native biodiversity (Crooks and Soulé 1999).

Like coyotes, gray foxes had a generalist diet, eating primarily mammals but also fruit and seeds, invertebrates, birds, and anthropogenic items. As with coyotes, dietary breadth of gray foxes was similar in small urban habitat fragments and larger control sites. However, gray foxes were less likely to occur in larger fragments in this system (Crooks 2002) and thus sample size was low in such sites, limiting our ability to compare across fragment types. Domestic cats, although uncommon in the gray fox diet, were found in scats only from the small urban patches. We are unable to determine whether the instances of large or domestic prey items, such as black-tailed deer and domestic cats, are instances of scavenging by gray foxes rather than direct predation. Regardless, the omnivorous, opportunistic diet and behavioral plasticity of gray foxes makes them particularly tolerant of urbanization (Crooks 2002, Riley et al. 2003, Riley 2006, Ordeñana et al. 2010, Gehrt et al. 2010). Consequently, gray foxes can persist within urban areas, particularly areas with reduced coyote activity given the potential for interference competition and intraguild predation (Crooks and Soulé 1999, Farias et al. 2005). We detected gray fox remains in one coyote scat in a small urban fragment, apparently reflecting such an instance of intraguild aggression.

Bobcats appear to be a specialist of mammalian prey, which occurred in all scat analyzed. Consistent with prior studies of urban bobcats (Riley et al. 2010), rodents (primarily Cricetidae) and lagomorphs were the predominant mammalian prey found in bobcat scats. However, lagomorphs were less frequent than in prior studies of urban bobcats in southern California, which studies have tended to identify rabbits as the most important prey item (Riley et al. 2010). This discrepancy potentially reflects a greater availability of rodents than lagomorphs in our study sites. Other food sources for bobcats included invertebrates and birds. Seeds were found in one scat, although most likely the seeds occurred in the stomach of a mammalian prey item (this scat contained both rodent and lagomorph remains) or were ingested incidentally. We are unable to determine the effect of fragment size on the diet of bobcats given that bobcats were largely absent from small urban fragments (Crooks 2002). Bobcats are more sensitive to urbanization than gray foxes and coyotes (Crooks 2002, Riley et al. 2003), and our study demonstrates that bobcats are less likely to exploit anthropogenic subsidies such as trash, cultivated fruits, and human commensals such as domestic cats. Such resource specializations likely 
contribute to the patchy distribution of bobcats and increase their vulnerability to anthropogenic disturbances (Crooks 2002), thus limiting their ability to persist in small urban patches compared to more opportunistic carnivores such as coyotes and gray foxes.

\section{ACKNOWLEDGMENTS}

We thank A. Brayshaw and the U.S. Geological Survey Western Ecological Research Center for help with scat collection and processing, and S. Riley for helpful comments on the manuscript. The research would not have been possible without the cooperation of Miramar Marine Air Corps Station, the Nature Reserve of Orange County, Point Loma Ecological Reserve, Starr Ranch Audubon Sanctuary, and Torrey Pines State Reserve. We also thank the San Diego Natural History Museum for reference samples and providing space for initial processing. This work was supported in by part by the NSF Ecology of Infectious Disease research program (NSF EF-0723676; EF-1413925) and a Colorado State University Monfort Professorship, The Kosciuszko Foundation, and EU resources under the European Social Fund (POKL.04.01.01-00-053/09).

\section{Literature Cited}

BaKer, R.O., AND R.M. Timm. 1998. Management of conflicts between urban coyotes and humans in southern California. Proceedings of the Eighteenth Vertebrate Pest Conference 18:299-312.

Bateman, P.W., and P.A. Fleming. 2012. Big city life: carnivores in urban environments. Journal of Zoology 287:1-23.

Beier, P., K.L. Penrod, C. Luke, W.D. Spencer, and C. CABAÑERo. 2006. South coast missing linkages: restoring connectivity to wildlands in the largest metropolitan area in the USA. Pages 555-586 in K.R. Crooks and M. Sanjayan, editors, Connectivity conservation. Conservation Biology Series. Cambridge University Press, Cambridge, UK. dx.doi.org/ 10.1017/CBO9780511754821.025

BeкоғF, M. 1977. Canis latrans. Mammalian Species 79:1-9.

Bolger, D.T., A.C. Alberts, R.M. Sauvajot, P. Potenza, C. McCalvin, D. Tran, S. Mazzoni, and M.E. Soule. 1997. Response of rodents to habitat fragmentation in coastal southern California. Ecological Applications 7:552-563.

Bonnington, C., K.J. Gaston, and K.L. Evans. 2013. Fearing the feline: domestic cats reduce avian fecundity through trait-mediated indirect effects that increase nest predation by other species. Journal of Applied Ecology 50:15-24.

Cномко, S.A. 1980. Identification of North American rodent teeth. Pages 72-99 in B.M. Gilbert, editor, Mammalian osteology. Modern Publishing, Laramie, WY.
Crooks, K.R. 2002. Relative sensitivities of mammalian carnivores to habitat fragmentation. Conservation Biology 16:488-502.

Crooks, K.R., AND M.E. Soulé. 1999. Mesopredator release and avifaunal extinctions in a fragmented system. Nature 400:563-566.

Czech, B., P.R. Krausman, and P.K. Devers. 2000. Economic associations among causes of species endangerment in the United States. BioScience 50: 593-601.

Danner, D.A., AND N. DoDD. 1982. Comparison of coyote and gray fox scat diameters. Journal of Wildlife Management 46:240-241.

FAHRIG, L. 2003. Effects of habitat fragmentation on biodiversity. Annual Review of Ecology, Evolution, and Systematics 34:487-515.

Farias, V., T.K. Fuller, R.K. Wayne, and R.M. Sauvajot. 2005. Survival and cause-specific mortality of gray foxes (Urocyon cinereoargenteus) in southern California. Journal of Zoology 266:249-254.

Fedriani, J.M., T.K. Fuller, and R.M. Sauvajot. 2001. Does availability of anthropogenic food enhance densities of omnivorous mammals? An example with coyotes in southern California. Ecography 24: 325-331.

Fritzell, E.K., and K.J. Haroldson. 1982. Urocyon cinereoargenteus. Mammalian Species 189:1-8.

GehrT, S.D., AND S.P.D. Riley. 2010. Coyotes (Canis latrans). Pages 79-95 in S.D. Gerht, S.P.D. Riley, and B.L. Cypher, editors, Urban carnivores: ecology, conflict, and conservation. Johns Hopkins University Press, Baltimore, MD.

Gehrt, S.D., S.P.D. Riley, AND B.L. Cypher. 2010. Urban carnivores: ecology, conflict, and conservation. Johns Hopkins University Press, Baltimore, MD.

Gehrt, S.D., E.C. Wilson, J.L. Brown, and C. ANChor. 2013. Population ecology of free-roaming cats and interference competition by coyotes in urban parks. PLOS ONE 8:e75718.

Halfpenny, J. 1986. A field guide to mammal tracking in North America. Johnson Books, Boulder, CO.

Klare, U., J. Kamler, and D. MacDonald. 2011. A comparison and critique of different scat-analysis methods for determining carnivore diet. Mammal Review 41: 294-312.

LaRIVIÈRE, S., AND L.R. WaLton. 1997. Lynx rufus. Mammalian Species 563:1-8.

LUKASIK, V.M., AND S.M. ALEXANDER. 2011. Human-coyote interactions in Calgary, Alberta. Human Dimensions of Wildlife 16:114-127.

MaYer, W.V. 1952. The hair of California mammals with keys to the dorsal guard hairs of California mammals. American Midland Naturalist 48:480-512.

McClure, M.F., N.S. Smith, AND W.W. ShaW. 1995. Diets of coyotes near the boundary of Saguaro National Monument and Tucson, AZ. Southwestern Naturalist 40:101-104.

McDonald, R.I., P. Kareiva, and R.T.T. Forman. 2008. The implications of current and future urbanization for global protected areas and biodiversity conservation. Biological Conservation 141:1695-1703.

Moore, T.D., L.E. Spence, C.E. Dugnolle, and W.G. HEPWORTH. 1974. Identification of the dorsal guard hairs of some mammals of Wyoming. Wyoming Game and Fish Department Bulletin 14:117-136.

Murie, O.J. 1954. A field guide to animal tracks. Houghton Mifflin, Boston, MA. 
NEALE, J.C.C., AND B.N. SACKs. 2001. Resource utilization and interspecific relations of sympatric bobcats and coyotes. Oikos 94:236-249.

Ordeñana, M.A., K.R. Crooks, E.E. Boydston, R.N. Fisher, L.M. Lyren, S. Siudyla, C.D. Haas, S. Harris, S.A. HathaWaY, G.M. TurschaK, ET AL. 2010. Effects of urbanization on carnivore species distribution and richness. Journal of Mammalogy 91: 1322-1331.

PIANKA, E.R. 1973. The structure of lizard communities. Annual Review of Ecology and Systematics 4:53-74.

Poessel, S.A., S.W. Breck, T. Teel, S. Shwiff, K.R. Crooks, AND L. ANGEloni. 2013. Patterns of humancoyote conflict in the Denver metropolitan area. Journal of Wildlife Management 77:297-305.

Quinn, T. 1997. Coyote (Canis latrans) food habits in three urban habitat types of western Washington. Northwest Science 71:1-5.

Rezendes, P. 1992. Tracking and the art of seeing: how to read animal tracks and sign. Camden House, Rochester, NY.

RILEY, S.P.D. 2001. Spatial and resource overlap of bobcats and gray foxes in urban and rural zones of a national park. Pages 32-39 in A. Woolf and C. Nielsen, editors, Proceedings of bobcat research symposium. Illinois Natural History Survey, Champaign-Urbana, IL.

RILEY, S.P.D. 2006. Spatial ecology of gray foxes and bobcats in urban and rural zones of a national park. Journal of Wildlife Management 70:1425-1435.

Riley, S.P.D., E. Boydston, K.R. Crooks, and L.M. Lyren. 2010. Bobcats (Lynx rufus). Pages 121-138 in S.D. Gerht, S.P.D. Riley, and B.L. Cypher, editors, Urban carnivores: ecology, conflict, and conservation. Johns Hopkins University Press, Baltimore, MD.

Riley, S.P.D., R.M. Sauvajot, T.K. Fuller, E.C. York, D.A. Kamradt, C. Bromley, and R.K. Wayne. 2003. Effects of urbanization and habitat fragmentation on bobcats and coyotes in southern California. Conservation Biology 17:566-576.

RiLEy, S.P.D., AND P.A. White. 2010. Gray foxes (Urocyon cinereoargenteus) in urban areas. Pages 197-198 in S.D. Gerht, S.P.D. Riley, and B.L. Cypher, editors, Urban carnivores: ecology, conflict, and conservation. Johns Hopkins University Press, Baltimore, MD.
Schipper, J., J.S. Chanson, F. Chiozza, N.A. Cox, M. Hoffman, V. Katariya, J. Lamoreux, A.S.L. Rodrigues, S.N. Stuart, H.J. Temple, et al. 2008. The status of the world's land and marine mammals: diversity, threat, and knowledge. Science 322:225-230.

Silverstein, R.P. 2004. The dispersal of seeds by coyotes, Canis latrans. Master's thesis, San Diego State University, San Diego, CA.

Soulé, M.E., D.T. Bolger, A.C. Alberts, R. Sauvajot, J. Wright, M. Sorice, and S. Hill. 1988. Reconstructed dynamics of rapid extinctions of chaparralrequiring birds in urban habitat islands. Conservation Biology 2:75-92.

Suarez, A.V., D.T. Bolger, and T.J. Case. 1998. The effects of habitat fragmentation and invasion on the native ant community in coastal southern California. Ecology 79:2041-2056.

Teerink, B.J. 1991. Hair of west-European mammals. Cambridge University Press, Cambridge, United Kingdom.

Tigas, L.A., D.H. Van Vuren, and R.M. Sauvajot. 2002. Behavioral responses of bobcats and coyotes to habitat fragmentation and corridors in an urban environment. Biological Conservation 108:299-306.

Tumlison, R. 1983. An annotated key to the dorsal guard hairs of Arkansas game mammals and furbearers. Southwestern Naturalist 28:315-323.

van Dijk, J., K. Hauge, A. Landa, R. Anderson, and R. MAY. 2007. Evaluating scat analysis methods to assess wolverine Gulo gulo diet. Wildlife Biology 13: $62-67$.

Wilcove, D.S., D. Rothstein, J. Dubow, A. Phillips, and E. Losos. 1998. Quantifying threats to imperiled species in the United States. BioScience 48:607-615.

Zabala, J., and I. Zuberogoitia. 2003. Badger, Meles meles (Mustelidae, Carnivora), diet assessed through scatanalysis: a comparison and critique of different methods. Folia Zoologica 52:23-30.

Received 27 June 2014 Accepted 23 May 2015 